\title{
A Disposição Virtual e o Direito à Desconexão Como Fator Gerador da Jornada Extraordinária dos Professores da Rede Privada de Ensino
}

\section{The Virtual Disposition and the Right to Disconnection as a Factor Generator of the Teachers' Extraordinary Working Day of the Private Education Network}

\author{
Márcio Barboza da Silva*a; Fabíola Cristina Carrero Taques ${ }^{\mathrm{b}}$ \\ ${ }^{a}$ UNICESUMAR, Pós-Graduação Lato Sensu em Direito Civil, Processual Civil e Direito do Trabalho. PR, Brasil. \\ ${ }^{\mathrm{b} C e n t r o ~ d e ~ E n s i n o ~ S u p e r i o r ~ d e ~ A p u c a r a n a, ~ C u r s o ~ d e ~ D i r e i t o . ~ P R, ~ B r a s i l . ~}$ \\ *E-mail: marciobarboza@icloud.com
}

\begin{abstract}
Resumo
Este trabalho visa analisar o direito à desconexão do docente da rede privada de ensino, ou seja, o direito de não trabalhar, tendo em vista que a Constituição da República Federativa do Brasil de 1988 garante tal direito, limitando a jornada de trabalho e garantindo o direito ao lazer e ao descanso. Como objetivo geral se pretende explicar que a jornada de trabalho do professor da rede privada de ensino é disciplinada pela Consolidação das Leis Trabalhistas. Como objetivos específicos se propõe verificar que a disposição virtual do professor da rede privada de ensino deve ser indenizada, pois o docente tem seu tempo de lazer mitigado, seja pelos alunos e seus responsáveis, ou por seus superiores hierárquicos através dos meios de comunicação eletrônicos; analisar o princípio da desconexão no Brasil por meio do Direito comparado com a lei francesa. Para realizar este estudo, foi realizada uma pesquisa bibliográfica e jurisprudencial, além do embasamento na CLT, na Convenção Coletiva de Trabalho do Sindicato dos Professores de Londrina - Paraná, em conformidade com a CRFB/88, bem como uma análise de direito comparado com a legislação francesa. Com isso, busca-se ratificar que o professor da rede privada de ensino tem seu direito à desconexão desrespeitado. Neste sentido, obtém-se como resultado parcial deste estudo que o uso dos aplicativos de comunicação virtual fora do horário de trabalho para atender alunos, pais e a própria instituição deve ser analisado dentro do perfil de jornada extraordinária. Verifica-se, ainda, a importância da proteção do trabalhador, em especial do professor, principalmente quando se trata da saúde.
\end{abstract}

Palavras-chave: Direito à Conexão. Disposição Virtual. Jornada Extraordinária.

\begin{abstract}
This work aims at analyzing the teacher's right to disconnect from the private school system, that is, the right not to work, given that the 1988 Federal Constitution of Brazil assures this right, limiting the working day guaranteeing the right to leisure and rest. As a general objective, it is intended to explain that the private school teacher's working day is disciplined by the Consolidation of Labor Laws. As specific objectives, it proposes to verify that the virtual disposition private education system teacher must be compensated, since the teacher has his or her leisure time mitigated, either by the students and their responsible ones, or by their hierarchical superiors through the electronic means of communication; to analyze the disconnection principle in Brazil through Law compared with the French law. In order to carry out this study, a bibliographical and jurisprudential research was carried out, in addition to the CLT, in the Collective Labor Convention of the Teachers' Union Trade of Londrina - Paraná, in accordance with CRFB / 88, as well as an analysis of law compared to the French law. Thus, it is tried to ratify that the private network education teacher has his or her right to the disconnection disrespected. In this sense, it was accomplished as a partial result of this study that the use of virtual communication applications outside working hours to attend students, parents and the institution itself should be analyzed within the profile of extraordinary working day. It was also verified the importance of worker protection, especially of the teacher, especially when it comes to health
\end{abstract}

Keywords: Right to Connection. Virtual Layout. Extraordinary Journey.

\section{Introdução}

Os meios de comunicação através de aplicativos, principalmente os de smartphones, são cada vez mais utilizados, tornando possível se comunicar rapidamente com praticamente qualquer pessoa do convívio social. É absolutamente mais rápido e, evidentemente, mais barato para as empresas entrarem em contato com seus colaboradores através de aplicativos eletrônicos, como por exemplo, o aplicativo Whatsapp, amplamente utilizado nos dias atuais.

Muitas instituições de ensino da rede privada incentivam a atualização desses aplicativos por parte de seus professores, pois a maioria dos alunos está conectada a todo momento, tornando quase impossível ministrar as aulas sem ter que chamar a atenção de um ou outro estudante para que ele se desconecte durante as aulas. Assim, para que os professores não se distanciem tanto da realidade dos alunos, as escolas se valem de lousas digitais conectadas à internet e, ainda, se utilizam com muita frequência dos chamados "grupos do whatsapp".

A Constituição Federal de 1988 (BRASIL, 1988) protege o direito de não trabalhar (desconectar), pois de acordo com José Filho (2014), quando o trabalhador deixa o local onde trabalha, terminado seu turno, tem iniciado seu período de descanso, ficando a cargo dele o que deseja fazer com esse período. Sendo assim, a desconexão é extremamente necessária para o trabalhador ter seu direito de lazer respeitado.

Geralmente, oprofessor tem uma carga de trabalho adicional 
que, normalmente, cumpre em seu período de descanso. Sem entrar no mérito das horas atividades dos professores da rede pública, que ficará para estudos posteriores, a rede privada de ensino vem se distanciando de um centro de ensino, tornandose uma educação terceirizada e se aproximando cada vez mais de uma empresa, visando, muitas vezes, somente o lucro, à custa da saúde de seus funcionários, principalmente dos seus docentes. Portanto, o trabalhador fica à mercê de abusos do polo patronal, que não possui nenhum tipo de controle nos envios de mensagens, sobretudo, no tocante ao horário de seus envios.

$\mathrm{O}$ interesse pelo tema do direito à desconexão do professor da rede privada de ensino partiu de observação diária, através da convivência com professores, do exagero da necessidade da continuidade de trabalho por meio da conexão a aplicativos eletrônicos com o objetivo de atender aos superiores hierárquicos, pais e alunos em seu momento de lazer e descanso.

A relevância deste trabalho para o meio acadêmico está em contribuir com as recentes pesquisas em Direito do Trabalho, mais especificamente, do direito à desconexão, tema este que ainda não tem legislação específica no Brasil.

Nesse sentido, este estudo teve por objetivo analisar o direito à desconexão dos professores da rede de ensino privada. Para tanto, foi necessário verificar a desconexão no Brasil por meio do Direito comparado com a lei francesa, e analisar jurisprudência sobre a desconexão como fator gerador de jornada extraordinária para professores da rede de ensino privada através de aplicativos eletrônicos.

\section{Desenvolvimento}

\subsection{Metodologia}

Partindo do princípio de que a desconexão é um direito do trabalhador, e que a jornada extraordinária deve ser indenizada, questiona-se: até que ponto a conexão dos professores da rede privada de ensino em seu horário de descanso e lazer, através de aplicativos eletrônicos, torna-se abuso do polo patronal?

Para responder a essa questão, a metodologia utilizada é de cunho qualitativo, a partir de pesquisa bibliográfica e análise de jurisprudência sobre a desconexão e jornada extraordinária. Para realizar a análise jurisprudencial, foi feita uma pesquisa no sítio do Tribunal Superior do Trabalho (TST), da qual foram selecionados três acórdãos que versam sobre o tema de forma genérica, pois não há julgados sobre o uso de aplicativos eletrônicos por parte dos professores da rede privada de ensino, gerando jornada extraordinária.

O método utilizado é o indutivo, por generalizar a partir de observações de casos da realidade concreta.

Para tanto, primeiramente, será feita uma contextualização da rede privada de ensino como uma empresa e não mais como uma instituição que visa educação como direito do cidadão, que deve, por meio do ensino, apropriar-se socialmente e culturalmente dos conhecimentos transmitidos pela escola. Em seguida, será feito um apanhado sobre o profissional professor do século XXI, observando seu trabalho enquanto educador, a partir das exigências contemporâneas. Após este capítulo, será feita uma explanação a respeito do princípio constitucional do direito à desconexão e da jornada extraordinária no Brasil. Então, far-se-á a análise de jurisprudências recentes do TST. Por fim, será feita uma comparação da Lei Francesa (L. 2242$8)^{1}$ que trata da desconexão com o regramento normativo pátrio.

Espera-se, através deste estudo, não esgotar o tema, mas contribuir para futuras pesquisas na área trabalhista, compreendendo que o direito à desconexão é constantemente desrespeito, prejudicando não só o tempo de lazer e descanso do professor, mas também sua saúde física e psíquica.

\subsection{A Docência no Século XXI}

O Direito do Trabalho tem como finalidade garantir a melhor condição de trabalho, como postula Martins (2017, p.66), ensinando que os fundamentos do Direito do Trabalho garantem melhores condições aos obreiros, "assegurando que o trabalhador possa prestar seus serviços em um ambiente salubre". Assim, as deficiências e negligências podem ser corrigidas através da proteção das leis trabalhistas.

Em relação ao trabalho do professor da rede privada de ensino, verifica-se que algumas escolas exploram seus próprios docentes. Nesse sentido, Silva e Pereira (2014, p.15) afirmam que "as instituições privadas visam o lucro e veem os alunos como clientes", e como toda empresa, quer cativar ao máximo seus clientes.

Portanto, essa condição a que o professor é submetido vai de encontro aos fundamentos do Direito do Trabalho, que por sua vez deve proteger os empregados dos abusos do polo patronal ou de quem quer que seja, já que no caso dos docentes os excessos não são somente da empresa, mas, em alguns casos, ainda estimula tais fatos, permitindo que pais e alunos tenham os contatos eletrônicos dos seus professores.

\subsection{A Internet e o Professor do Século XXI}

As tecnologias móveis evoluíram rapidamente no início do século XXI. Atualmente, é comum a utilização dos Smartphones, seja no meio pessoal ou no profissional, não sendo utilizados apenas os telefones celulares, mas também tablets, leitores de livros digitais, aparelhos portáteis de áudio, entre outros. E a rede privada de ensino também vem se adequando à evolução tecnológica, permitindo - e fornecendo - acesso à internet nas salas de aulas através das "lousas digitais". Para Carvalho e Tavares Melo (2018, p.2): “A inserção das Tecnologias da Informação e Comunicação (TIC) na escola permitiu o acesso às ferramentas tecnológicas", 
tornando necessária a mudança na forma de ensinar e aprender.

O aplicativo WhatsApp favorece a comunicação entre professores, direção escolar, alunos e seus responsáveis. Para Melo e Rodrigues $(2018$, p.), a tecnologia proporciona um trabalho menos penoso, sendo que: "A tecnologia fornece à sociedade meios mais confortáveis de viver". Quando essa tecnologia, no caso o WhatsApp, é utilizada "fora dos padrões responsáveis, pode provocar desajustes na ordem social" (MELO; RODRIGUES, 2018, p. 47).

Para Melo e Rodrigues (2018), o smartphone é, sem dúvida, um grande transformador cultural, deixando de ser um simples telefone, visto que essa função é a de menor relevância atualmente, mudando o comportamento das pessoas. Portanto, no caso do professor da rede privada de ensino, a comunicação entre os seus alunos, pais e direção, acompanhou a evolução tecnológica.

\subsection{Jornada de Trabalho}

Segundo a CRFB/88, a jornada de trabalho é de oito horas diárias e quarenta e quatro horas semanais (art. $7^{\circ}, \mathrm{XIII}$, CRFB/88). De acordo com Martins (2017, p. 750): “As 44 horas semanais a que faz referência a Constituição não tem o nome de jornada, pois não são diárias, mas semanais". Desse modo, a melhor denominação seria módulo semanal ou duração semanal do trabalho.

Algumas profissões têm características próprias para o labor diário, como explica Martins Filho (2014, p.188), que se deve levar em conta "o desgaste produzido, a maneira, o local e o tipo de atividade, o limite máximo de horas é diverso". Verifica-se, por exemplo, que os músicos (art. 41. Lei $n^{\circ} 3.857 / 60$ ) e os jornalistas, artigo 303, da Consolidação das Leis do Trabalho (CLT) têm sua jornada de trabalho de 05 horas diárias, assim como a jornada do professor, que têm suas particularidades.

\subsubsection{A jornada de trabalho do professor}

O professor tem sua jornada de trabalho disciplinada no art. 318 da CLT, que sofreu alteração recente pela Lei $\mathrm{n}^{\mathrm{o}} 13.415 / 17$, estabelecendo uma nova redação, na qual o professor poderá lecionar, na mesma instituição de ensino, por mais de um turno, assegurado a ele o horário de refeição, desde que essa jornada respeite a duração semanal do trabalho, que é de 44 horas.

Em análise da Convenção Coletiva de Trabalho (CCT) 2018-2019, do Sindicato dos professores de Londrina/PR (SINPRO-LDNPR), entende-se que o horário de trabalho do professor é o da jornada de trabalho contratada ${ }^{2}$, em conformidade com a CLT, que no art. 320 consta que a remuneração do docente ocorre pelo número de aulas semanais, fortalecendo que esse tem sua duração de trabalho diversa. Portanto, se o professor é contratado para lecionar 12 aulas semanais, em determinado estabelecimento de ensino, sua jornada de trabalho será de 12 horas/aula semanais, em que todos os seus vencimentos (FGTS, 13º, salário, férias etc.), terão por base essa jornada.

\subsubsection{Jornada extraordinária}

O funcionário cede sua força laboral por determinado período e por um preço estipulado. Logo, o empregado está naquele tempo contratado, prestando serviços ao empregador, e assim que encerrada a jornada de trabalho, o trabalhador não estará mais à disposição do poder diretivo do empregador.

Tal é a importância da duração do trabalho que a CLT dedica um capítulo a esse tema ${ }^{3}$, dos artigos 57 a 75 . Visto a necessidade de proteção à saúde do empregado, Leite (2017, p. 495) entende que para salvaguardar o funcionário; “As normas referentes à duração do trabalho humano têm por escopo principal proteger a integridade física e psíquica do trabalhador".

O trabalho exercido fora do período contratado, seja antes ou após a jornada de trabalho, é considerado jornada extraordinária, surgindo para o empregado, em regra, o recebimento do adicional de hora extra. A hora extra deve ser acrescida de, no mínimo, 50\% do valor da hora normal (art. $\left.7^{\circ}, \mathrm{XVI}, \mathrm{CRFB} / 88\right)$.

Horas extras, no conceito explicado por Martins (2017, p. 770): "são as prestadas além do horário contratual, legal ou normativo", que serão devidas pelo empregador com o adicional respectivo. Assim, a disposição virtual do professor da rede privada de ensino, além de ferir o direito à desconexão, merece ser indenizada na forma de hora extraordinária.

\subsection{As Horas-Atividades e a Jornada Extraordinária do Professor}

O exercício do magistério possui certas particularidades, tanto é que a CLT dedicou a Seção XII para disciplinar a matéria em relação aos professores. No entanto, alguns pontos ficaram a cargo de CCT, como é o caso das horas/atividades.

A jornada do professor da rede privada de ensino excede o tempo que ele passa em sala de aula, seja preparando aulas e pesquisa, corrigindo e elaborando provas. A remuneração para essas atividades extras do professor é conhecida por horaatividade, que no caso da rede privada é cumprida, geralmente, em local diverso da instituição. A CCT do SINPRO-LDNPR prevê o pagamento da hora atividade sobre o salário base do docente de, no mínimo, $10 \% 4$.

Assim, no caso da jornada extraordinária do professor da rede privada de ensino, ainda mais no que tange à disposição

2 A CCT 2018-2019 refere-se sempre em hora/aula, estabelecendo os valores a serem percebidos pelos docentes.

3 A CLT dedica o Capítulo II "DA DURAÇÃO DO TRABALHO” para disciplinar a Jornada de Trabalho.

4 CCT - SINPRO-LDNPR. 2.3. DA HORAATIVIDADE: fica assegurado um adicional de no mínimo $10 \%$ do salário base do docente, para cumprimento de hora/atividade. 
virtual, pois os meios eletrônicos de comunicação, como por exemplo, o aplicativo WhatsApp, são extremamente utilizados pelos pais, alunos e superiores hierárquicos, para interação com os professores. Como explica Borsoi (2012, p.86): “Um computador conectado à internet e um telefone são suficientes para que mantenham um elo com a instituição, onde quer que estejam". Nesse sentido, para Sako (2014, apud MELO; RODRIGUES, 2018, p.63), com a tecnologia empregada no trabalho "o ser humano teria mais tempo para o ócio", mas em vários casos e, principalmente, em relação à disposição virtual, o referido autor exemplifica que fica evidenciado que "o uso de novas tecnologias, o ritmo de trabalho aumentou, bem como o tempo livre foi reduzido", gerando assim, uma integração sem limites entre os professores, pais, alunos e direção escolar, e docente é o lado mais afetado por essa disposição, já que lhe é privado o tempo de desconexão por meio dessa tecnologia de comunicação.

\subsubsection{Remuneração}

Para se referir à forma de pagamento pelos serviços prestados pelo empregado ao empregador, utilizam-se vários termos: subsídios é o nome dado ao pagamento dos magistrados ${ }^{5}$; honorários quando se fala em profissionais liberais e vencimentos para os professores, por exemplo. A CLT utiliza a palavra remuneração. Para Martins (2017), o art. 457 da CLT usa o termo remuneração, que se constitui em um conjunto de vantagens. Essas vantagens são aquelas pagas diretamente pelo empregador (salário) e as pagas por terceiros, que são as gorjetas. Mesmo o art. 457 da CLT não definindo o que é remuneração e salário, revelou os elementos que o integram ${ }^{6}$. A remuneração é o conjunto de prestações recebidas habitualmente pelo empregado pela prestação de serviços.

Os componentes que integram a remuneração e o salário podem ser divididos em duas espécies: a primeira é de caráter não salarial, que incorpora apenas a remuneração, portanto, de natureza indenizatória ou ressarcitória, relacionadas também à educação, ao transporte, à assistência médica e as pagas por terceiros (gorjetas), entre outros. Já a de natureza salarial inserem-se no complexo de formação do salário do obreiro, como por exemplo: o salário base, as comissões, horas extraordinárias, etc. (LEITE, 2017).

Sendo assim, remuneração é gênero e salário é espécie. Nesse sentido, Manus (2015) postula que fazer a diferenciação entre esses dois vocábulos é essencial no mundo jurídico, pois a maioria dos doutrinadores faz essa distinção, mas completa explicando que

seria a remuneração o conjunto dos títulos que percebe o empregado por sua prestação de serviços, aí incluído, como principal, o salário. Este - devido e pago pelo empregador, diretamente, pela prestação de serviços (MANUS, 2015, p.120).

Isso posto, deixa-se de lado se há relevância ou não na terminologia de salário e remuneração, se são sinônimos ou não, pois se prefere a referência doutrinária de que essa divisão é essencial no Direito do Trabalho, mesmo que alguns empregadores se valham da possibilidade de enquadrar alguns ganhos dos seus funcionários como pagamentos não salariais, para, assim, furtarem-se de cumprir a lei. A Lei $n^{\circ}$ 13.467 de 2017 (Reforma Trabalhista) modificou a redação dos $\S \S 1^{\circ}, 2^{\circ}$ e $3^{\circ}$ do artigo 457 da CLT, pois a redação do $\S$ $1^{\circ}$, antes da reforma, explicava que salário é todo pagamento feito pelo empregador, com habitualidade, sem exigir qualquer nomenclatura específica, ficando exigido somente o pagamento com habitualidade.

Assim, o tipo de remuneração pode variar, a depender da forma de prestação do trabalho, por exemplo: pode o funcionário trabalhar por dia, semana, quinzena ou mês, ou ainda por hora, por tarefa ou peça. No caso do professor da rede privada de ensino, a remuneração é pelo número de aulas semanais, conforme previsão da CLT no art. 320 caput.

\subsubsection{A remuneração do professor da rede privada de ensino}

A CLT prevê que o professor será remunerado pelo número de aulas semanais, considerando o mês de quatro semanas e meia, e pagos mensalmente ${ }^{7}$, sendo prerrogativa das entidades de classe estabelecer um piso salarial. Silva e Pereira (2014, p. 85) entendem que "a maioria das instituições de ensino privado não possuem políticas de valoração do docente" e, com isso, o professor da rede privada de ensino fica à vontade de interesses capitalistas das instituições privadas de ensino.

A maioria dos professores é contratada por hora/aula e, consequentemente, sua remuneração terá por base a quantidade de aulas que efetivamente ministrarem. A hora/ aula do professor da rede privada de ensino, com base na CCT 2018/2019 do SINPRO-LDNPR, a remuneração do professor da Educação Infantil e até o quinto ano do Ensino Fundamental será de R\$1.054,49, e o valor mínimo da hora/ aula é de R\$ 11,53. Nesse contexto, Silva e Pereira (2014, p.89) afirmam que "o salário pago ao professor não condiz com o papel que desempenha na sociedade".

Assim, quando o professor está fora do ambiente laboral, e tem seu tempo de lazer ocupado por mensagens enviadas por meios eletrônicos, sobre assuntos que deveriam ser tratados no local de trabalho, esse tempo deve ser indenizado, como bem explica Abramo (1999, apud ALMEIDA; SEVERO

\footnotetext{
5 De acordo com o Art. 95, III, da Constituição Federal.

6 Art. 457 - Compreendem-se na remuneração do empregado, para todos os efeitos legais, além do salário devido e pago diretamente pelo empregador, como contraprestação do serviço, as gorjetas que receber.

7 Art. 320 - A remuneração dos professores será fixada pelo número de aulas semanais, na conformidade dos horários.

$\S 1^{\circ}$ - O pagamento far-se-á mensalmente, considerando-se para este efeito cada mês constituído de quatro semanas e meia.
} 
2016, p.23), “a porção de vida que é dedicada ao trabalho é justamente o que determina 'o espaço e as possibilidades para todo o resto", Dessa forma, verifica-se que o labor do professor não é mero objeto, e quando é desrespeitado deve ser indenizado, atendendo, assim, o direito à desconexão.

\subsection{O Direito à Desconexão no Brasil}

O homem passa boa parte da sua vida trabalhando, vendendo sua força de trabalho para o empregador e, para assegurar a dignidade do trabalhador, é extremamente necessário o controle de jornada de trabalho e o tempo de descanso. Nesse sentido, Almeida e Severo (2016, p.13) verificam que o "trabalho é elemento de constituição do ser social" e da necessidade de trabalhar "para sobreviver e ainda conviver com nossos pares". Dessa forma, pode-se entender que o trabalho é elemento indispensável da dignidade da pessoa humana. É nesse ponto que se encontra o direito à desconexão que, impulsionado pelo avanço tecnológico e a facilidade de comunicação através dos aplicativos de smartphones, o trabalhador corre o risco de cada vez mais ter esse direito desrespeitado.

$\mathrm{O}$ art. $6^{\circ}$ da $\mathrm{CRFB} / 88$ trata dos direitos fundamentais sociais, que exigem uma participação essencial do Estado. Em uma sociedade de ideais capitalistas, este artigo tenta minimizar os impactos desenfreados dessa ideologia, valendose de princípios socialistas. De acordo com os autores Almeida e Severo (2016, p.10): "Nossa Constituição é um exemplo de um pacto entre o ideal capitalista e o ideal socialista de sociedade".

Para Souto Maior (2003, p.1): “ao falar em desconexão faz-se um paralelo entre a tecnologia, que é fator da vida moderna", mas, fora do trabalho, deve-se verificar que o homem tem o direito de não trabalhar, de se desconectar. Quando o empregado não está trabalhando, está desconectado, utiliza seu tempo para o lazer, o convívio familiar e social, devendo o patrão ou superior hierárquico não o privar desse tempo, seja através de ligações, e-mails ou mensagens de texto que façam o funcionário "reconectar-se" ao trabalho.

Atualmente, se tem 1 bilhão de usuários ativos por dia do aplicativo WhatsApp no Mundo $^{8}$, isso pela facilidade e agilidade na comunicação entre os usuários. A comunicação feita pelo aplicativo WhatsApp fora do tempo à disposição do empregador deve - e será - caracterizada como uma jornada extraordinária, pois somente através do controle da jornada de trabalho, principalmente do tempo de lazer, pode-se efetivar o Direito à Desconexão. O tema é de grande relevância, tanto que alguns países já legislaram sobre a desconexão. Neste trabalho, o exemplo legislativo será o da França, que "saiu à frente" do Brasil, e promulgou uma lei que protege os empregados dos abusos das empresas com relação à desconexão.

\subsection{A Disposição Virtual do Professor da Rede de Ensino Privada}

Como visto ao longo deste artigo, a profissão de professor tem a função de alicerce de todas as profissões, ou seja, a carreira de docente é um sacerdócio. A educação vem sendo tratada como parte de um negócio, visando apenas o lucro. Nesses termos, Silva e Pereira (2014, p.89) elucidam que a instituição de ensino "tem sua composição, assim como os outros negócios", instigando a competitividade e uma produção em massa que persegue a lucratividade.

A desconexão prevista na $\mathrm{CRFB} / 88$ garante que nas relações de trabalho exista uma limitação da duração do trabalho, e que o lazer é um direito social fundamental. Souto Maior (2003) define: "que o avanço tecnológico está roubando o trabalho do homem". Atualmente, percebe-se que "é a tecnologia que tem escravizado o homem ao trabalho". A vida moderna impõe uma excessiva conexão, por isso o tema é latente, e a proteção à desconexão, bem como a limitação da jornada de trabalho são se extrema relevância.

O tempo de lazer do professor da rede privada de ensino não é uma mercadoria para ser posta à disposição do empregador, ou dos alunos e seus responsáveis. O docente em seu horário de lazer tem que parar, quase sem perceber, para resolver problemas de trabalho, ou responder a e-mails. Como explicam Silva e Pereira (2014, p.15): “A exploração do professor por algumas escolas é um fato cotidianamente narrado pelos próprios docentes", e os pais e alunos se entendem por clientes, e os professores por seus empregados, tornando o professor quase um refém (virtual). Portanto, a disposição virtual do professor deve ser entendida como adicional de horas extras, e o texto constitucional garante que esse adicional seja remunerado, devendo incidir na base de cálculo das demais parcelas, podendo assim indenizar a disposição virtual do docente.

\section{Conclusão}

Não há dúvidas de que o empregado necessite de tempo para descansar, e se relacionar com sua família, pois ele precisa do seu tempo de lazer. Sendo isso incontroverso, a desconexão é um direito de defesa aos abusos do polo patronal. $\mathrm{O}$ abuso da disposição virtual deve ser contido e o mais rápido possível, já que os professores ficam à mercê de alunos, pais e superiores hierárquicos em todo o seu tempo de lazer. E ainda não há dúvidas de que para tal disposição deva ser acrescida a remuneração do professor através das horas extras, pois são prestadas além do horário contratado, verificando que a regra geral também se aplica aos professores da rede privada de ensino.

\section{Referências}

ALMEIDA, A.E.; SEVERO, V.S. Direito à desconexão nas 
Relações Sociais de Trabalho. São Paulo: LTr, 2016.

BORSOI, I.C.F. Trabalho e produtivismo: saúde e modo de vida de docentes de instituições públicas de ensino superior. Cad. Psicol. Soc. Trabalho, v.15, n.1, p. 81-100 2012.

BRASIL. Constituição da República Federativa do Brasil (1988). Promulgada em 05 de outubro de 1988. Disponível em: http:// www.planalto.gov.br/ccivil_03/Constituicao/ConstituicaoCompilado.htm. Acesso em: 25 abr. 2019.

BRASIL. Convenção Coletiva de Trabalho (2018-2019). Sindicato dos Estabelecimentos de Ensino do Norte do Paraná. Disponível em: <http://www.sinprolondrina.com.br/wp-content/ uploads/2018/07/CCT-SINPRO-SINEPE-2018-2019.pdf $>$ Acesso em: 08 out. 2018.

BRASIL, Consolidação das Leis do Trabalho. DECRETO-LEI $N^{\circ}$ 5.452, DE $1^{\circ}$ DE MAIO DE 1943. Disponível em: http:// www.planalto.gov.br/ccivil_03/decreto-lei/del5452compilado. htm. Acesso em: 25 de abr. 2019.

CARVALHO, L.S.F.B.; TAVARES MELO, M.A.T. O whatsapp como ferramenta motivadora no ensino da produção escrita. CIET:EnPED, 2018. Disponível em: http://cietenped.ufscar.br/ submissao/index.php/2018/article/view/727. Acesso em: 28 jul. 2019.

FRANCE. Code du travail. LOI n²016-1088 du 8 août 2016 - art. 55 (V). Disponível em: https://www.legifrance.gouv.fr/af-
fichCodeArticle.do?cidTexte=LEGITEXT000006072050\&idArticle $=$ LEGIARTI000033024095\&dateTexte $=\&$ categorieLien $=i d$. Acesso em: 8 jul. 2019.

JOSÉ FILHO, W.L. Breves notas sobre o direito à desconexão do trabalho. Disponível em: http://www.magistradotrabalhista.com. br. Acesso em: 25 abr. 2019.

LEITE, C.H.B. Curso de direito do trabalho. São Paulo: Saraiva, 2017.

MANUS, P.P.T. Direito do trabalho. São Paulo: Atlas, 2015.

MARTINS, S.P. Direito do trabalho. São Paulo: Saraiva, 2017.

MARTINS FILHO, I.G.S. Manual esquematizado de direito e processo do trabalho. São Paulo: Saraiva, 2014.

MELO, S.N.; RODRIGUES. K.R.A.L. Direito à desconexão do trabalho: com análise crítica da reforma trabalhista. São Paulo: LTr, 2018.

SILVA, L.M.M.; PEREIRA, M.T. Docência (in)digna: o meio ambiente laboral do professor e as consequências em seus direitos da personalidade. São Paulo: LTr, 2013.

SOUTO MAIOR, J.L. Do direito à desconexão do trabalho. 2013. Disponível em: https://www.jorgesoutomaior.com/ uploads/5/3/9/1/53916439/do direito à desconexão do trabalho..pdf. Acesso em: 9 jun. 2019. 